\title{
Obituary
}

\section{Dan G. McNamara, MD, MACC}

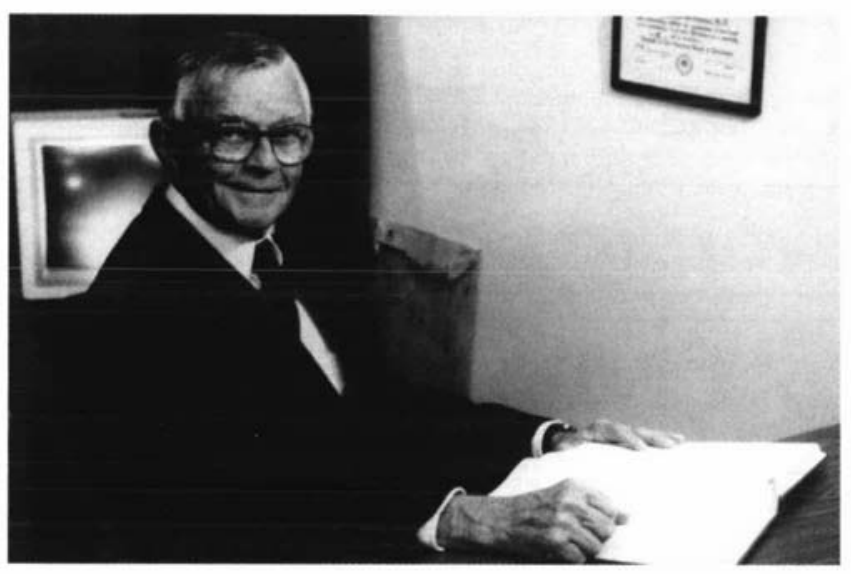

Dr Dan G. McNamara, MD, MACC

$\mathrm{I}$ N THE DEDICATION TO DAN MCNAMARA IN THE recent addition of our textbook we wrote: "The 1 Science and Practice of Pediatric Cardiology is a tribute to Dan G McNamara. The editors of both editions were his trainees, his faculty, or both. The list of contributors includes a great number of McNamara trainees as well. He was one of the great medical editors; it is our hope this edition is a fitting tribute to him."

Dan was born in a small town in Texas and was a graduate of Baylor University in Waco. He attended medical school at Baylor University College of Medicine shortly after it moved from Dallas to Houston, during the time that the medical school was temporarily housed in the old Sears warehouse in Houston. Dan occasionally joked about having done a respectable job for a guy who got his medical degree at a department store. After residency in St Louis and fellowship with $\mathrm{Dr}$
Taussig at Johns Hopkins, Dan returned to Houston and to the newly built Texas Children's Hospital. Dan soon teamed with Denton Cooley in the Department of Surgery to develop one of the world's pre-eminent heart programs for children. He not only built this program, established its values and its importance in treating both patients and physicians with ultimate care, as was natural for him, he assumed numerous positions of leadership. In 1981, he became President of the American College of Cardiology.

He was a father figure to several generations of pediatric cardiologists trained in Houston. $\mathrm{Dr}$ McNamara supplied wisdom, guidance, support, encouragement, enthusiasm, resources and boundaries to those of us who had the opportunity to begin our pediatric cardiac training and careers as part of "McNamara's band". He was a true mentor, teaching us to be subtle, firm and humorous all at the same time. He took pride in his trainees and colleagues, always giving us more than we deserved and keeping little for himself. Dan stepped down as Division Chief in 1987, but was an extremely important part of the Department as Emeritus Chief. He was a favourite teacher of the students, residents, fellows and faculty, and was teaching in the clinic up to the week when a stroke occurred that later led to his death on September 9, 1998. Our field is truly fortunate that Dan McNamara's career was dedicated to the science and practice of pediatric cardiology, and especially to the students and teachers of the next generation.

Artbur Garson, Jr, J. Timotby Bricker 